\title{
SEWPS
}

SPRU Electronic Working Papers Series

\author{
Paper No. 180
}

\section{Missing links in nanomaterials governance: bringing industrial dynamics and downstream policies into view}

\author{
Ismael Rafols ${ }^{a, b, 1}$, Patrick van Zwanenberg ${ }^{a, 1}$ \\ Molly Morgan ${ }^{a}$, Paul Nightingale ${ }^{a}$ and Adrian Smith ${ }^{a}$ \\ a SPRU - Science \& Technology Policy Research, \\ University of Sussex, Brighton BN1 9QE, UK \\ b TPAC, School of Public Policy, \\ Georgia Institute of Technology, Atlanta, GA 30332, USA
}

${ }^{1}$ Corresponding authors: $\underline{\text { i.rafols@ } @ \text { sussex.ac.uk and P.F.Van-Zwanenberg@ } \text { sussex.ac.uk }}$

February 2010

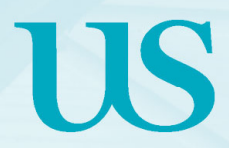

University of Sussex

SPRU - Science \& Technology Policy Research
SPRU, The Freeman Centre University of Sussex Falmer, Brighton, BN1 9QE w.e.steinmueller@sussex.ac.uk http://www.sussex.ac.uk/spru 


\begin{abstract}
In this article we explore some of the analytical and policy implications of widening the focus of nanomaterials governance from risk regulation to the broader issue of the purposeful direction of the innovation process. We focus on the impact of industrial activities on nanotechnology governance, arguing that the specific characteristics of the industrial dynamics of nanomaterials - flexibility in applications and distributed innovation - limit and enable different potential interventions to shape technology. In particular, these characteristics exacerbate the difficulties of attempting to directly influence innovation trajectories. Under these conditions, we argue that policies for nanomaterials governance need to be broadened. The prevailing emphasis in the UK on policy initiatives 'upstream' in the R\&D process, while commendable, should be complemented with policies aimed further 'downstream' at potential users of nanomaterials, such as renewable energy procurement or housing regulations in order to modulate technological development towards socially desirable goals.
\end{abstract}

Keywords: nanotechnology; manufactured nanomaterials; innovation governance; industrial dynamics; enabling technology; technology assessment; public engagement. 


\section{Introduction}

The development of nanotechnologies and nano-enabled products has been accompanied by considerable attention to their potential health, environmental, and social implications. In recent years an array of expert committee hearings and reports have addressed issues of nanotechnology governance, often with the primary focus being the management of risk (e.g. RS/RAE 2004; Renn and Roco 2006a; SCENIHR 2007; RCEP 2008). More recently, official and expert attention has began to grapple with how the regulatory and promotion aspects of innovation might be better integrated, such that the direction of innovation becomes a more explicit feature of nanotechnology governance (RCEP 2008). In this paper we too focus not on the governance of risk but more broadly on the governance of innovation for the specific case of manufactured nanomaterials in the UK context (rather than for nanotechnologies in general $^{1}$ )

Our aim here is to point out the explicit role of industrial dynamics in shaping technological choices. Studies of nanomaterials governance typically focus on risk appraisal (Renn and Roco 2006b; Hansen et al. 2008), regulation (Lee and Jose 2008; Stokes 2009) and public attitudes and deliberation, sometimes in relation to policy (Kahan et al. 2009; Pidgeon et al., 2009; Macnaghten et al. 2005; Doubleday 2007). A few studies have analysed the impact of industrial activity on risk governance, for example, in relation to life cycle assessment (Bauer et al. 2007; Meyer et al. 2009). However very few discuss the impact of industrial dynamics

\footnotetext{
${ }^{1}$ We focus on a specific subset of nanotechnologies, namely manufactured nanomaterials, which is at the centre of the debate of risk and governance. Nanomaterials are among the 'first' generation nanotechnologies, which have reached or are about to reach commercialisation and thus pose the most urgent threat. This does not mean that innovation governance analysis for other nanotechnologies, e.g. 'active nanotechnologies' ('second' generation), is not relevant. But it also does not follow that our analysis can be generalised. See Doubleday (2007) for a discussion on the framings of nanotechnologies.
} 
on the innovation process more generally (one exception is Robinson, 2009). In this paper, we argue how crucial these dynamics are for understanding nanomaterials governance - and suggest that their study has been under-developed.

Our argument is that specific characteristics of the industrial dynamics of nanomaterials have important implications for innovation governance, because they limit and enable different potential interventions that could be used to influence innovation trajectories. We define governance, as 'all structuring of action and interaction that has some authority and/or legitimacy' whether or not these actions or interactions are intentionally aimed at governing or regulating (Rip 2009, p. 2). Following Arie Rip (2009), we use the term 'de facto governance' in order to emphasise that governance occurs in the absence of, and/or extends beyond, formal or intentional regulatory or policy intervention. It follows that industrial dynamics are already playing a major role in shaping technological choices, whether or not conscious and purposive governance intentions are at play.

We argue that since nanomaterials are enabling technologies, they can be used for a variety of applications in myriad commercial sectors - and their function and use (and meaning) can be re-interpreted at different points in diverging value chains. Thus the industrial dynamics of the nanomaterials is characterised by flexibility of applications and distributed innovation. These characteristics have two implications. The first is that nanomaterials development is intractable in terms of our ability to shape the specific outcomes of nanomaterial innovation processes. Nevertheless, we argue that there is scope to broadly modulate innovation processes towards generic goals (Rip 2009). The second is that policy intervention to influence the direction of technological development should not only be aimed at influencing R\&D priorities. Innovation should not be assumed only to take place 'upstream' in the value 
chain, (Wilsdon and Willis 2004) or even midstream (Fisher et al. 2006; Joly and Rip 2008), but also downstream, closer to the end-user.

\section{A broader conceptualisation of nanotechnology governance}

Three main conclusions have repeatedly emerged from studies on the governance of nanotechnology. First, 'nanotechnology' is a palette of disparate technologies at the nanoscale and does not necessarily constitute a useful category to discuss regulation or technology governance (Doubleday 2007; RCEP 2008, p.12). Second, there is major uncertainty and ignorance regarding the potential impacts of many manufactured nanomaterials on health and the environment (RCEP 2008, p. 27; Hansen et al. 2008). Third, public concerns about both the potential risks and benefits posed by nanotechnologies are fundamentally about the purposes and interests behind innovation itself, and thus policy should be concerned more broadly with innovation governance rather than risk governance (EC 2007). Risk governance is traditionally concerned with minimising the risks of harmful effects of nanotechnologies hence it is a back-end response to innovation. Innovation governance, on the other hand, is aimed at purposefully influencing technological choices, such that innovation is directed to socially agreed purposes, benefits and priorities, whether these are concerned with competiveness, health, well-being, social justice or environmental sustainability.

This broader agenda for nanomaterials governance is already implicit in the term 'responsible development', often invoked by government and industrial discourses (EC 2008; Anon 2008, BASF 2009). 'Responsible development' is often understood as extending beyond the traditional regulatory remit of anticipating and mitigating adverse impacts of the new 
technologies (Rip, 2009). As the US National Research Council puts it, responsible development 'implies a commitment to develop and use technology to help meet the most pressing human and societal needs, while making every reasonable effort to anticipate and mitigate adverse implications or unintended consequences' (National Research Council 2006, p. 73). This discourse is often driven by instrumental concerns. In the wake of experiences with agricultural GM technologies there are anxieties in official and industrial circles about public acceptability of nanomaterials innovations. Public attitudes to the potential risks posed by nanomaterials (as in biotechnology) appear to differ widely depending on the application, and on the perceptions of who reaps the benefits and who bears the costs (RCEP 2008, p. 72; Stirling 2008). Not surprisingly under these circumstances, green nanotechnologies have become the new and acceptable side to 'nano' in contributing to the solution of the world's most pressing problems, such as clean water and climate change (Jones 2007; Schmidt 2007; Rebuffat 2008).

Such ambitions to influence the direction of innovation in novel materials are nevertheless beset by a pivotal dilemma (Collingridge, 1992). Early in the development stage, efforts to direct a technology in a particular direction are vulnerable to failure because both the technology's final form and its effects are unpredictable. Yet once a particular technology has become established, and we are able to learn more about its impacts, material investments, infrastructures, institutional commitments, routines and user habits develop around the development trajectory for the whole technological system, which means it is extremely difficult and costly to reverse or redirect (Dosi 1982; David 1985; Arthur 1989; Shove 2003).

In response to this dilemma a number of policy approaches have been proposed that try to broaden the range of perspectives and stake-holders in the processes of developing, and 
governing technology development; the aim being to avoid socially undesirable technological configurations before irreversible commitments have been made (see review in Fisher et al. 2006). In the case of the UK, strategies of public engagement 'upstream' have been proposed, intended to influence innovation processes in their earliest stages, before lock-in to certain technological trajectories can occur (Wilsdon and Willis 2004; Wilsdon et al. 2005; Macnaghten et al. 2005; Pidgeon et al. 2009). While these initiatives are a valuable contribution to innovation governance, they have tended to focus on those areas that are most amenable to direct intervention, such as public R\&D funding, corporate public relations, or product regulation.

Yet, other sites within nanomaterials value chains also play a major role in the shaping of innovation, via de facto governance processes (Rip, 2009). Here it is important to recognise that governance is in place even in the absence of intentional efforts to regulate, control or shape a technology because existing socio-technical networks both enable and constrain future technological developments (Smith et al, 2005). Furthermore, policies aimed at shaping the direction of innovation have to emerge from and act within a given configuration of de facto governance arrangements (Smith and Stirling 2007; Rip 2009). A variety of activities, such as the discourse on responsible development of nanotechnology and its associated corporate codes, expert committees in the International Organization for Standards, OECD working parties, etc., have been presented as examples of the emergence of a distributed form of governance for nanomaterials (RCEP 2008). If we broaden the scope from risk governance to innovation governance - given our interest in technological choice and adopt a de facto governance perspective, it follows logically that not just soft law, standards and associated social arenas, but also a variety of structuring institutions and sites 
need to be taken into account. A map of the actors playing roles in innovation helps to identify these sites (see Figure 1 in this piece, and Figure 2 in Robinson 2009. p.10).

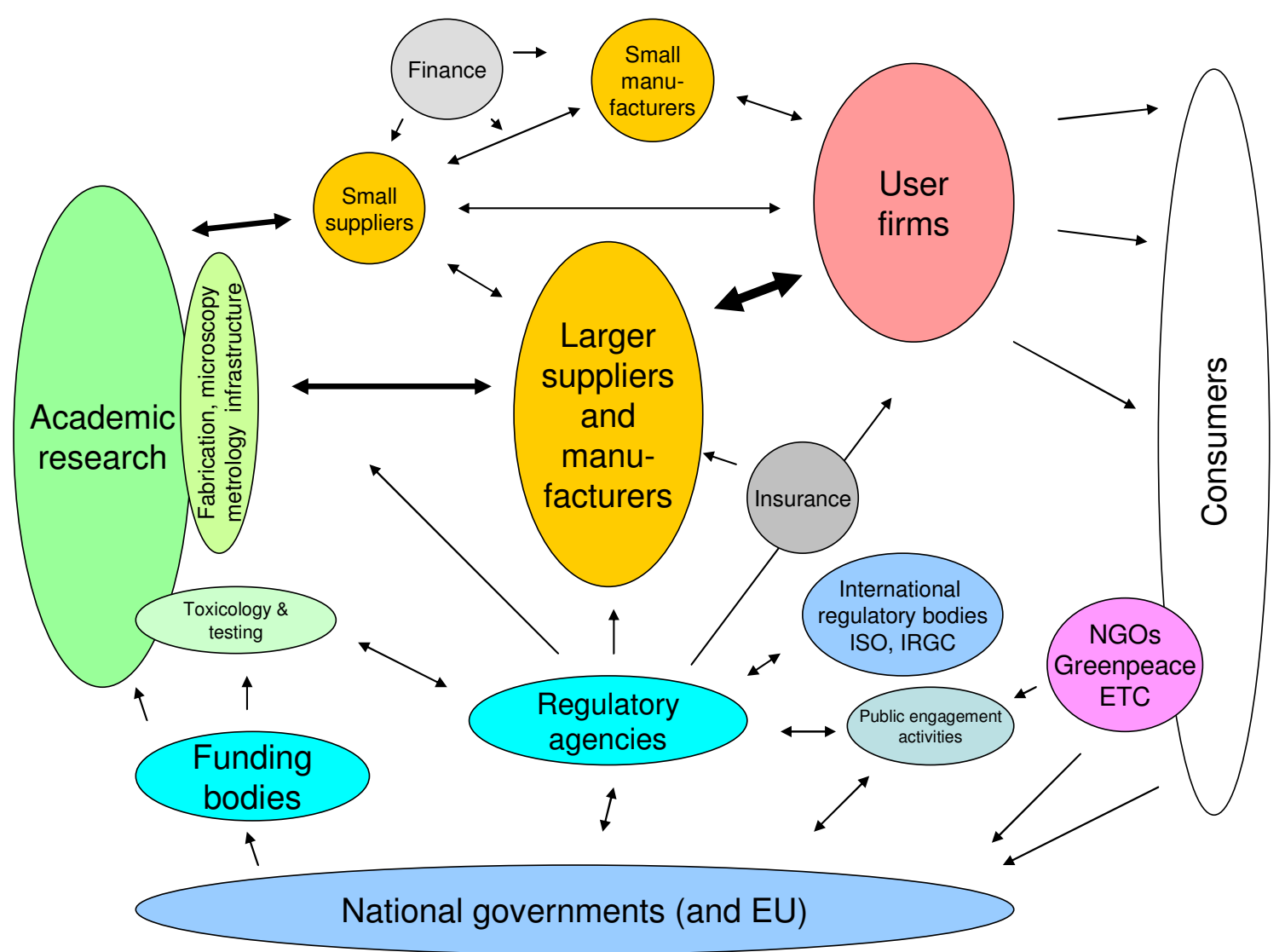

Figure 1. Generic actors and main linkages in nanomaterials innovation and governance networks.

For governments attempting to foster and support certain applications of nanomaterials it is easier to try to intervene and influence public research funding and regulatory agencies which are under their direct control. ${ }^{2}$ However, it should be emphasised that the core of nanomaterials innovation networks are configured by the various industrial actors, which consequently play a central role in de facto governance. In summary, a de facto governance perspective highlights the crucial role played not just by $R \& D$ activities, but also firms

\footnotetext{
${ }^{2}$ E.g., since 2008 the UK Engineering and Physical Science Research Council (EPSRC) has had programmes (Grand Challenges) devoted to the application of nanotechnologies in Energy, Healthcare and the Environment.
} 
manufacturing nanomaterials, the firms making nano-enabled products and other actors such as the insurers, retailers and end-users. This is why industrial dynamics are such an important site for setting directionality.

\section{Industrial dynamics: flexibility in applications and distributed innovation}

The key issue regarding industrial dynamics is that manufactured nanomaterials are not consumer products that are sold to end-users, but 'capital' products that are incorporated into other products manufactured by secondary firms in a variety of industries. Nanomaterials are generally not used to produce radically new commercial products, but to improve the quality of existing products. Products containing nanomaterials can be intermediary products (i.e. functional components such as biosensors or light emitting diodes) or end-user products (e.g. nano-silver socks or solar cells) whose performance is enhanced by the specific properties of the nanomaterials. In other words, nanomaterials are enabling technologies. This has two important implications for the structure (and governance) of their value chains in terms of their flexibility of application and the distributed nature of innovation.

Flexibility of application means that one type of nanomaterial can be used in a variety of applications that can benefit from the same special electronic, optical, catalytic, chemical or physical properties of the material. This flexibility is two way: since the same specific and special properties are provided by different nanomaterials, choice exists among the materials to be selected to fulfil a given function. For example, carbon nanotubes can be used for applications in drug delivery, photovoltaics and sensors (among others). But for the specific application of photovoltaics, one could use different nanomaterials such as metal oxides 
nanoparticles or quantum dots, instead of carbon nanotubes. Aitken et al. (2006, p. 303) list 27 possible applications across 20 categories of nanomaterials, with about 10 different applications for each category, many of them overlapping with other categories. This extraordinary flexibility of application allows for the exploitation of economies of scope by suppliers.

The Manchester-based company Nanoco offers a good example of how a specific nanomaterial covers a wide range of applications (www.nanocotechnologies.com). Nanoco develops and produces quantum dots, which are semiconductor nanoparticles with special electronic and optical properties, in particular fluorescence of a very characteristic wavelength. This property is valuable to many different applications. Thus, Nanoco has developed the use of quantum dots for photovoltaic cells, lighting, displays, biomedical imaging, drug discovery, anti-counterfeiting and sensors (for example, in pollution monitoring). Another example is Dr Saif Haque of Imperial College London. Haque's research focuses on charge transfer dynamics in nanostructured molecular materials (nanocrystalline $\mathrm{TiO}_{2}$ ) with the goal of developing solar cells. However, his better understanding of the properties of nanocrystalline $\mathrm{TiO}_{2}$ prompted him to branch his research into chemical sensors (e.g. for security checks in airports) and light-emitting displays (e.g. for consumer electronics) -which have completely different social implications.

This diversity of applications and economic sectors is the reason why the industrial structure in nanomaterials tends toward vertical disintegration of firms along the value chain. The case of the company IOTA Nanosolutions Ltd. (www.iotanano.com ), a spin off of Unilever, illustrates this. A collaboration between the consumer products multinational Unilever and the University of Liverpool led in 2002 to development of a method to form nano-dispersions 
of insoluble materials into a range of liquids. Since better dispersion leads to an increase of bio-activity, it is potentially valuable for improving the effect (or reducing the bulk amount) of antimicrobials, fungicides, insecticides, and antiparasitic agents present in home care and personal care products -key areas in the Unilever's portfolio. But this technology is also potentially useful to products not directly competing with Unilever's, and in sectors were Unilever is not active, for example in pharmaceuticals (since better dispersion helps improve the bioavailability of ethical drugs, and control better their release). Thus, Unilever set Iota Nanosolutions as an independent firm catering for multiple sectors, whilst still controlling a majority share, rather than develop and commercialise Nanosolutions technology within the framework of Unilever .

Flexibility of application, by definition, is characteristic of so-called enabling or general purpose technologies which have been shown to generate surges in productivity (David and Wright 1999; Youtie et al. 2008) and episodes of vertical disintegration (Rosenberg 1963). As we will see, one of the key consequences of flexibility is that the 'final outcomes of innovation are not realized until the stages of final implementation/configuration', and may differ substantially from the initial technological visions or promises (Williams, 2006, p. 238).

The distributed nature of innovation in nanomaterials results from the long, branching value chains into which nanomaterials are incorporated. For example, $\mathrm{TiO}_{2}$ nanoparticles, developed in a collaboration between a university spin-off and a transnational chemical corporation, are bought by manufacturers of ceramic tiles or glass (because they provide selfcleaning properties), who sell their products to construction companies in multiple countries, who sell their buildings to real estate agents, who sell them on to households, who hire people 
(or do it themselves) who may drill into the tiles or windows, remove them and generally redecorate their new homes. In these long industrial networks, innovation occurs at different stages along the value chain ${ }^{3}$ - innovation results not only from the synthesis of new nanomaterials (e.g. single wall carbon nanotubes - SWCNTs), but also from new production processes (e.g. use of new catalysts for SWCNTs production), new ways of incorporating well-known nanomaterials into existing products (e.g. SWCNTs in paper or plastics), new methods of incorporating nanomaterials into products (e.g. ink jet printing of SWCNT), or more rarely - new end-user products made possible by the properties of nanomaterials (e.g. fully recyclable electronic newspapers enabled by the SWCNT printable memory). ${ }^{4}$

The fragmented and divergent networks in nanomaterials are very different from those in other distributed industries, such as pharmaceuticals or telecommunications, where large firms operate as system integrators than bring together the different pieces of the value chain -and in practice also heavily shape the governance. In the case of nanomaterials, there are also large companies such as Unilever, DuPont or Bayer who play indeed a major role, but they are surrounded by user firms, and by small supplier and manufacturing firms with a high degree of autonomy. ${ }^{5}$ The overall picture is one of a highly distributed structure without coherence nor integration (or integrators) -which has implications on the discussion of governability in the next section.

This lack of systemic co-ordination between supplier, manufacturers and/or users generates problems of understanding of the potential usages of nanomaterials, both in terms of realising

\footnotetext{
${ }^{3}$ Robinson (2009, pp. 7-8) proposes a richer description of the value chain in terms of an 'innovation chain' that constitutes a 'mosaic of arenas of innovation and selection'.

${ }^{4}$ This example is based on media coverage of the report by Song et al. (2008) on inkjet printing using SWCNTs.

${ }_{5}^{5}$ Informally, large firms in nanomaterials typically point out these small actors as the most likely source of potential mis-handlings of health and environmental risk.
} 
the benefits and avoiding risks. In order to address the challenge of co-ordination, supplier firms have evolved from seeing themselves as suppliers of materials to seeing themselves as suppliers of technological solutions using (materials) properties. In a way, in doing this they are effectively moving closer to a service firm that offers to work "closely with its customers to develop bespoke nanomaterials for specific applications" (Nanocentral, 2010).

One of the consequences of highly distributed value chains, compounded by potential ubiquity, is that one end-user product such as a car or a house may have incorporated many different nanomaterials. This occurs in the same way that they incorporate many different chemicals or ICTs: not as one coherent, easily identifiable technology, but by accretion of diverse intermediate technologies: in one house we will have one nanomaterials use for energy photovoltaics, two for insulation, one for self-cleaning, one to prevent corrosion, etc. (as illustrated in Table 1). Heterogeneity of nanomaterials in end-user products means that nanotechnologies cannot be governed at the end-product level. Instead, it is in each of the branching 'junctures' of the value-chain, that a given nanomaterial is subject to multiple pressures and constraints that push, pull and shape its development in certain directions. These influences include the scientific and technical paradigms and routines that frame researchers' thinking (Dosi, 1982); dedicated infrastructures that make substitution with alternatives difficult (Jacobsson and Johnson, 2000); practices that enjoy greater economies of scale and positive network externalities (Arthur, 1989); prevailing social practices (Shove, 2003); dominant policies, legal frameworks and professional association lobbying (Walker, 2000); and hegemonic discourses that inform socially acceptable performance criteria. ${ }^{6}$ Hence, at every stage in the value chain - up-, mid- and downstream, these various factors lead to specific commitments that might result in different types of lock-in: to the particular

\footnotetext{
${ }^{6}$ E.g., Doubleday (2007) and Robinson (2009) argue that there is lock-in in the policy discourse: the framing of nanomaterials governance is focused narrowly on health, environment and safety issues.
} 
nanomaterials used; to the type of energy or labour required for their production infrastructures; to the possibilities for the product to be recycled; to the types of applications favoured; and so on.

Table 1. Examples of nanomaterials products used in housing. Source: Meyer et al. (2008).

\begin{tabular}{|l|l|l|l|}
\hline Product & Nanomaterial & Function & Company \\
\hline Col.9 Dispersions & Silicon oxide nanoparticles & $\begin{array}{l}\text { Paints with reduced dirt } \\
\text { pick-up }\end{array}$ & BASF (Germany) \\
\hline Ccflex & $\begin{array}{l}\text { Nanoparticle based sol gel } \\
\text { chemistry }\end{array}$ & Ceramic wallpaper & Degussa (Germany) \\
\hline Erlus Lotus & $\begin{array}{l}\text { Titanium dioxide } \\
\text { nanoparticles }\end{array}$ & Self-cleaning roof tiles & Erlus (Germany) \\
\hline StoPhotosan/StoLotusan & $\begin{array}{l}\text { Titanium dioxide } \\
\text { nanoparticles }\end{array}$ & Self-cleaning facade & Sto (Germany) \\
\hline Hydrotect & Titanium dioxide & Self-cleaning tiles & $\begin{array}{l}\text { Deutsche Steinzeug } \\
\text { (Germany) }\end{array}$ \\
\hline Pilkington Active & Titanium dioxide thin-film & Self-cleaning glass & Pilkington (UK) \\
\hline Bioni Hygienic & Nano silver & $\begin{array}{l}\text { Antimicrobial and } \\
\text { antibacterial } \\
\text { coating/paint }\end{array}$ & Bioni CS (Germany) \\
\hline MMFX High Strength & $\begin{array}{l}\text { Nanoscale laminated lath } \\
\text { structure }\end{array}$ & $\begin{array}{l}\text { High corrosion } \\
\text { resistance }\end{array}$ & MMFX Steel Corp (USA) \\
\hline Solara & Nanoporous silicon dioxide & Anti-reflex coating & CentroSolar Glass (Germany) \\
\hline Climaplus & $\begin{array}{l}\text { Infrared-reflective silver nano } \\
\text { coatings }\end{array}$ & Heat insulation & Saint Gobain Glass (France) \\
\hline Nanogel & Silica aerogel & Heat insulation & Cabot Nanogel (Germany) \\
\hline
\end{tabular}

In spite of the importance of understanding nanomaterial value chains, both for risk and innovation considerations, there has been little scholarly work on their nature and dynamics (for exceptions see Schmid and Reidiker, 2008; Robinson 2009). Research has been conducted on the industrial dynamics of nanotechnology in sociology and economics, but it focuses on the conditions for 'success' for public researchers, firms or clusters on the basis of bibliometric and patent analyses (reviewed in Meyer et al. 2008). In our view, this body of work has produced only limited insights relevant to considerations of governance. This lack of research on innovation networks and value chains is compounded by the secrecy in nanomaterials trade between manufacturing and user firms, and the fact that most countries (so far) have been reluctant to insist on mandatory reporting by firms of nanomaterial applications (UK Government 2009, 19-22), preferring instead to opt for voluntary schemes 
that have failed to provide any meaningful information (DEFRA 2008). This means that there is very little information on the scale and scope of nanomaterials applications (Maynard and Rejeski 2009). The only public database of nanotech-enabled products is based on information from firms' web sites (PEN 2009) whilst estimates by private consultants on nanomaterials markets differ by orders of magnitude (Meyer et al. 2008). Here we have only provided anecdotal evidence of the crucial role played in governance by industrial value chains, but we believe that an empirical, systematic research on the industrial dynamics of nanomaterials is needed.

\section{Policies for nanotechnology}

\subsection{The limits of government}

Given the conditions of distributed innovation and flexibility in applications, it is worthwhile asking whether is it actually possible to purposefully govern the development of nanomaterials. Some nanotechnologies have emerged under environments where the number of innovating, manufacturing and commercialising companies and other stakeholders is comparatively small and easy to identify. In these cases, one can imagine the possibility of purposefully directing innovation towards specific outcomes via policy interventions that anticipate alternative applications. This might be typical of relatively bounded systems, such as specific energy (e.g. fuel cells) or sanitation (e.g. membrane) technologies, which have well-defined societal functions, or even in generic applications very specifically framed (e.g. 'lab-on-a-chip for cell analysis', Robinson and Propp 2008). However, in the case of most nanomaterials, with an overwhelming multiplicity of innovation sites and actors (distributed innovation), and wide diversity of outcome options and societal functions (flexibility of 
application), our knowledge is too incomplete and the web of interactions too complex to assume that efforts to 'control' the directions of technology will succeed in driving innovation towards the desired options.

Even if our knowledge of how nanomaterials are being used (and of risks, benefits, and social preferences) was massively improved, the would-be governance actors would still find the task of controlling and purposefully making choices aimed at specific outcomes overwhelming. This is because the combined properties of distributed innovation and flexibility exacerbate the multiplicity of actors, complementary technologies and linkages involved in developing or using nanomaterials. Historical examples of other emergent technologies displaying general purpose characteristics, such as chemicals, ICTs and biotechnology, provide vivid illustrations of the sheer unpredictability of social outcomes, and challenge the assumption that collective action can purposefully shape technological directions (Williams 2006). Yet accepting the incapacity to exert control over the specific outcomes of nanomaterials, does not negate the possibility of modulating their development more broadly towards generic goals.

\subsection{Directing Innovation}

We suggest that there is scope for policy to influence the direction of nanomaterials innovation, but policy would need to accomplish three tasks: a) to negotiate and identify socially acceptable and socially unacceptable potential trajectories of nanomaterials innovation, b) to foster those deemed acceptable, and c) to discourage those deemed unacceptable. We will not dwell on the first of these here, but such a task is likely to require deliberative public forums in which a wide range of perspectives and stakeholders can engage 
with the social, political and ethical dimensions of nanotechnologies (see, for example, the discussion in RCEP 2008). Fostering and discouraging particular pathways would require that existing policy initiatives are broadened and more closely integrated in at least two respects, as we outline below.

\section{Upstream and downstream policies}

In the UK, ambitions to steer nanotechnology innovation in socially-desired directions have focused, in recent years, on public engagement 'upstream', in the R\&D process (Wilsdon and Willis 2004; Macnaghten et al. 2005; Pidgeon et al. 2009). The aim, at least for its academic champions, is to encourage scientists to reflect on public values and aspirations about the social purposes of technology, with a hope for subsequent influence on the articulation and pursuit of R\&D problems. The proponents of public engagement (at least the academic social scientists) initially used the term 'upstream' to refer to the 'early stages' of a technology, that is, before commitments to specific problems, products and applications had become entrenched, or at "a point where research trajectories are still open and undetermined" (Wilsdon et al. 2005, p. 38). However, the notions of 'upstream' and 'downstream' have not always been clearly defined $^{7}$ and are frequently conflated in policy practice with the use of 'upstream' in the terminology of industrial value chain analysis (which pre-dated the 'engagement' usage). Within the 'value chain' terminology, downstream refers to those stages closer to the end-user (left-hand side of Figure 1), and upstream to those that lie far from the consumer (right-hand side of Figure 1). This is the meaning we have adopted here reserving 'early stage' to refer to the phase before technological lock-in.

\footnotetext{
${ }^{7}$ One exception is Fisher et al. (2006), for whom 'upstream' is associated with research policy, 'midstream' with R\&D practice and 'downstream' with commercial and/or social applications and regulation. Note that this use is slightly different from ours.
} 
Within the so-called linear model of innovation, which assumes a directional flow of knowledge from science to technology to society, it is easy for non-experts to conflate 'upstream' and 'early-stage' as referring to the same phase, that is, the phase when the technologies are initially developed in the R\&D process. However, the linear model has been widely discredited by many historical studies - most technologies are developed and shaped throughout the value chain, in interactions downstream (e.g. between users and manufacturing firms), as well as midstream (between firms and finance) and 'upstream' (between firms and researchers). Indeed, the description in Section 3 of how innovation occurs at numerous loci in the value chain, in no predetermined order, implies that the concepts of 'early stage' and 'upstream' should not be confused. The directions of nanomaterials and nano-enabled-products are shaped at the up-, mid-, and downstream sites and policy intervention (and deliberative practices) may be required 'early-stage' - but in all these sites in order to modulate de facto governance.

\section{Linking promotional and regulatory policies}

The governance of technologies traditionally has been split between promotional policies that support research, mainly upstream in the value chain, and regulatory policies aimed downstream to ensure the safe and sustainable use of new technologies (Fisher et al. 2005). Too often, these two faces to innovation governance are considered separately and sequentially, which tends to build extra conflict into governance arrangements. In practice, the promotion of certain technologies constrains the development of others, whilst strict regulation of emerging or existing technologies often indirectly promotes the development of alternatives. A closer coupling of these two faces to innovation governance is already underway. Under the aegis of the precautionary approach, enshrined in EU legislation, risk governance has broadened risk appraisal processes to include a wider variety of sites and 
social actors, from downstream end-users to researchers and policy makers operating further upstream. Calls for early warning systems, and 'adaptive innovation governance', respond to this logic (RCEP, 2008). The analysis developed in the previous two sections suggests that a reciprocal move is also necessary: in order to influence direction, technology promotional policies are needed not only upstream but also mid- and downstream.

Our analysis of the UK's promotional policies for nanomaterials, conducted for the RCEP, revealed a strong focus upstream, that is, the left-hand side of Figure 1: funding for basic and applied research; investment for shared facilities and infrastructures; and grants for university-industry collaboration (Nightingale et al. 2008). We found no promotional policies targeted further downstream, where value-chains and markets unfold. Whilst there may be scope for policy designed to promote technology further downstream, the associated unpredictable dynamics of distributed innovation means that any such interventions cannot be geared to the achievement of specific outcomes for nanomaterials. Instead downstream policy needs to address generic frameworks that will have a modulating effect on the development of nanomaterials. This is because policies mid- and downstream (and sometimes upstream), need to support certain social functions such as transportation, energy provision and health, without being necessarily specific about the technologies that can provide them.

\section{Fostering and discouraging innovation trajectories}

In order to illustrate how a richer and more closely integrated palette of promotional and regulatory interventions might steer nanomaterial innovation, let us assume, for example, that the development of nanostructured photovoltaic devices for use in sectors such as energy or housing has been identified as a socially desirable innovation trajectory. Nanostructured 
photovoltaic devices have the potential to increase the efficiency of photovoltaic technologies by collecting light from a broader range of wavelengths than conventional cells, and could also substantially reduce manufacturing costs. Thus far, however, research into commercial photovoltaic technology has not been undertaken to any great extent by industry and the capital investment required by the photovoltaics industry is prohibitively high given the commercial uncertainties involved (Oakdene and Hollins 2007). More generally, the use of photovoltaic devices of whatever kind in sectors such as energy or housing remains, at best, a niche activity.

Given the distributed nature of innovation, potential policy measures span both sides of Figure 1 -some are specific to nanomaterials, some are specific to energy or housing, some are generic - either up- or downstream. Policies specific to nanomaterials, mainly up- and midstream, would include metrology equipment, toxicology studies, clearing-houses to facilitate awareness and knowledge flows among universities, manufacturing firms and potential user-firms - which, as argued above, constitute the current policy focus. Also, and equally relevant, would be policies specific to renewable technologies, such as:

- $\quad$ targeted research funding for both public and private R\&D;

- the conduct of extended foresight or technology assessment exercises on the topic of renewable energy provision/photovoltaics to influence the direction of search processes among potential users and suppliers of nano-structured photovoltaic technologies

- underwriting of some commercial risks, or grants, to invest in the production capacity required to produce photovoltaics incorporating nanomaterials; 
- public procurement (e.g. street lighting or government buildings) to encourage the formation of markets. The creation of these niche markets can allow the learning and product development necessary to enter successfully into broader-based markets;

- clearing-houses to facilitate awareness and knowledge flows between manufacturing firms and potential user-firms;

- targeted regulations, such as a requirement for the incorporation of renewable energies into certain kinds of future housing stock (again, the effect being to encourage investors to move into the niche activity of photovoltaic technology and provide space to create broader-based markets);

- fiscal policies designed to have the same market-creating effect, e.g. incentives to individual households wishing to invest in photovoltaics;

- policies that create dialogue between up-, mid-, and down-stream innovation governance activities, such that each makes explicit the opportunities for the other.

In addition, it would be important for these policies to be aligned to generic sustainability policies and pressures within the 'user' sectors (far right-hand side of Figure 1), specific to the energy or housing sectors. This latter include, for example, policies to promote the internalisation of carbon emissions in the strategic decisions of business, or more specifically, requirements to install micro-renewables in new buildings. The challenge is to make explicit how nanomaterials can provide solutions to problems whose saliency and urgency is given prominence by broader sustainability policy.

Finally, we note briefly that the elephant in the room is that policy efforts to support particular desired generic configurations needs to be accompanied by measures that discourage less desirable trajectories. This is not only in the sense that particular directions of 
nanomaterial innovation may be deemed socially unacceptable, but also because there may be incumbent technological configurations preventing the emergence of those nanomaterial applications and uses that are deemed desirable.

\section{Conclusions}

A feature of both scholarly and policy debate on the governance of nanotechnology is the shift of attention beyond risk considerations and towards governing the unfolding directions of technological futures. Yet it is far from clear how ambitions to influence nanomaterials innovation in the direction of socially agreed priorities and benefits might be realised. Current discourse about 'responsible development' and public engagement is unlikely, by itself, to suffice in the face of conflicting commitments in other societal sites.

In this article we have explored how the industrial dynamics shape the de facto governance of nanomaterials. We suggest that a focus on industrial networks all along the value chains provides illuminating ways in which to think about directing innovation. Specifically, we claim that the characteristics of the industrial dynamics of nanomaterials - flexibility in application and distributed innovation - have implications for our understanding of how public policy might affect innovation governance. These characteristics exacerbate the difficulties of exerting control and making narrow choices. This suggests that policy initiatives to shape innovation processes should emphasise the modulation of technologies towards desirable social functions rather than the achievement of specific applications. Moreover, such policies should be aimed at the multiplicity of sites in which innovation takes places. In particular, policy initiatives upstream are not sufficient to direct innovation. They 
need to be complemented by downstream policies such a procurement or targeted regulations. Our analysis suggests that a broader understanding of governance and a richer palette of policies are required if the public policy is to move beyond preventing risk to shaping the social outcomes of nanomaterials development.

\section{Acknowledgements}

This article is based on research carried during a scoping study for the Royal Commission on Environmental Pollution carried out in 2008 (see Nightingale et al. 2008). We thank A. Rip and D. Robinson for discussions and comments.

\section{References}

Aitken, R. J., Chaudhry, M. Q., Boxall, A. B. A. and Hull, M. (2006). Manufacture and use of nanomaterials: current status in the UK and global trends. Occupational medicine, 56: 300-306.

Anon (2008) The Responsible Nano Code. http://www.responsiblenanocode.org. Accessed 8 July 2009.

Arthur, W.B. (1989) Competing technologies, increasing returns, and lock-in by historical events. The Economic Journal 99 (394): 116-131.

BASF (2009) Code of Conduct Nanotechnology. http://www.basf.com/group/corporate/en/sustainability/dialogue/in-dialogue-withpolitics/nanotechnology/code-of-conduct. Accessed 8th July 2009.

Bauer, C., Buchgeister, J., Hischier, R., Poganietz, W. R., Schebek, L. and Warsen, J. (2007). Towards a framework for life cycle thinking in the assessment of nanotechnology. Journal of Cleaner Production, 16(8-9): 910-926.

Collingridge, D. (1992). The Management of Scale: Big Organizations, Big Decisions, Big Mistakes. . London, Routledge.

David, P.A. (1985). Clio and the economics of QWERTY. The American economic review 75(2): 332-337.

David, P. and Wright, G. (1999) General purpose technologies and surges in productivity: histotical reflections on the future of the ICT revolution. University of Oxford, Discussion Papers in Economic and Social History, 31. Available at http://www.nuffield.ox.ac.uk/economics/history/paper31/a4.pdf. Accessed 30 January 2010.

DEFRA (2008). "The UK Voluntary Reporting Scheme for Engineered Nanoscale materials: Seventh Quarterly Report." Accessed 6 September 2008.

Dosi, G. (1982). Technological paradigms and technological trajectories A suggested interpretation of the determinants and directions of technical change. Research Policy, 11(3), 147-162 
Doubleday, R. (2007). Risk, public engagement and reflexivity: Alternative framings of the public dimensions of nanotechnology. Health, Risk \& Society, 9(2): 211 - 227.

EC (2007). Taking European knowledge society seriously. Report of the Expert Group on Science and Governance to the Science. Brussels, Economy and Society Directorate, DG for Research, EC.

EC (2008) Commission recommendation of a code of conduct for responsible nanosciences and nanotechnologies research. EC, Brussels 02/02/2008 C(2008) 424 final.

Fisher, E., Mahajan, R. L. and Mitcham, C. (2006). Midstream modulation of technology: governance from within. Bulletin of Science, Technology and Society, 26(6): 485-496.

Jacobsson, S. and Johnson, A. (2000). The diffusion of renewable energy technology: an analytical framework and key issues for research. Energy Policy, 28, 625-640.

Joly, P.-B. and Rip, A. (2007). A timely harvest. Nature, 450: 74.

Jones, R. (2007). Can nanotechnology ever prove that it is green? Nature Nanotechnology, 2: 71-72

Hansen, S.F., Maynard, A., Baun, A. and Tickner, J.A. (2008). Late lessons from early warnings for nanotechnology. Nature Nanotechnology 3: 444-447.

Kahan, D. M., Braman, D., Slovic, P., Gastil, J. and Cohen, G. (2009). Cultural cognition of the risks and benefits of nanotechnology. Nature Nanotechnology, 4: 87-90.

Lee, R. and Jose, P. D. (2008). Self-interest, self-restraint and corporate responsibility for nanotechnologies: Emerging dilemmas for modern managers. Technology Analysis \& Strategic Management, 20(1): 113-125.

Macnaghten, P., Kearnes, M. B. and Wynne, B. (2005). Nanotechnology, Governance, and Public Deliberation: What Role for the Social Sciences? Science Communication, 27(2): 268-291.

Maynard, A. and D. Rejeski (2009). Too small to overlook. Nature 460: 174.

Meyer, M., Makar, I., Rafols, I., Olsen, D., Wagner, V., Zweck, A., Porter, A. L. and Youtie, J. (2008). Euronano: Nanotechnology in Europe: assessment of the current state, opportunities, challenges and socio-economic impact, ETEPS.

Meyer, D. E., Curran, M. A. and Gonzalez, M. A. (2009). An examination of existing data dor the industrial manufacture and use of nanocomponents and their role in the life cycle impact of nanoproducts. Environmental Science and Technology, 43(5): 12561262.

Nanocentral (2010) Qinetiq Nanomaterials Ltd. http://www.nanocentral.eu/wpcontent/uploads/qinetiqnanomaterials.pdf Accessed 29 January 2010.

National Research Council. (2006) A Matter of Size: Triennial Review of the National Nanotechnology Initiative. Washington, D.C. National Academies Press.

Nightingale, P., Morgan, M., Rafols, I. and van Zwanenberg, P. (2008). Nanomaterials Innovation Systems: Their Structure, Dynamics and Regulation. Report for the Royal Commission on Environmental Pollution. Brighton, UK, SPRU. Available at: http://www.sussex.ac.uk/spru/documents/spru-rcep-nanomaterials.pdf

Oakdene Hollins (2007).Environmentally Beneficial Nanotechnologies: Barriers and Opportunities. Report for DEFRA. Available at http://www.defra.gov.uk/environment/nanotech/policy/pdf/envbeneficial-report.pdf

PEN (2009) Consumer Products. An inventory of nanotechnology-based consumer products currently on the market. Woodrow Wilson International Center for Scholar. Project on Emergent Technologies, Washington DC. Accessed 8 July 2009. http://www.nanotechproject.org/inventories/consumer/

Pidgeon, N. Herr Harthorn, B., Bryant, K., Rogers-Hayden, T. (2009) Deliberating the risks of nanotechnologies for energy and health applications in the United States and United Kingdom. Nature Nanotechnology 4: 95-98. 
RCEP (2008). Novel materials in the environment: The case of nanotechnology. UK, Royal Commission on Environmental Pollution. Available at http://www.rcep.org.uk/reports/27-novel\%20materials/27-novelmaterials.htm.

Rebuffat, F. (2008) The risk and promise of green nanotechnology. Research*eu 56: 22-24.

Renn, O. and Roco, M. (2006a) White Paper on Nanotechnolog y Risk Governance. International Risk Governance Council.

Renn, O. and Roco, M. (2006b). Nanotechnology and the need for risk governance. Journal of Nanoparticle Research, 8, 153-191.

Rip, A. (2009). De facto governance in nanotechnologies. Preprint of the Proceedings of the Tilburg Institute for Law, Technology and Society (TILT) Conference.

Robinson, D.K.R. and Propp, T. (2008) Multi-path mapping for alignment strategies in emerging science and technologies. Technological Forecasting and Social Change 75: 517-538.

Robinson, D. K. R. (2009). Co-evolutionary Scenarios: An application to prospecting futures of the responsible development of nanotechnology. Technological Forecasting and Social Change, Forthcoming.

RS/RAE (2004).Nanoscience and nanotechnologies: opportunities and uncertainties, Royal Society and Royal Academy of Engineering. Available at http://www.nanotec.org.uk/. Accessed 11 July 2008.

Rosenberg, N. (1963) Technological change in the machine tool industry, 1840-1910. The Journal of Economic History, 23 (4), 414-443.

SCENIHR (2007). Opinion on the appropriateness of the risk assessment methodolog y in accordance with the technical guidance documents for new and existing substances for assessing the risks of nanomaterials, European Commission Scientific Committee on Emerging and Newly Identified Health Risks (SCENIHR). Available at http://ec.europa.eu/health/ph_risk/committees/04_scenihr/docs/scenihr_o_010.pdf.

Schmid, K. and Riediker, M. (2008). Use of nanoparticles in Swiss industry: a targeted survey. Environmental Science and Technology, 42(7), 2253-2260.

Schmidt, K.F. (2007) Green nanotechnology: it's easier than you think. Woodrow Wilson International Center for Scholar. Project on Emergent Technologies, Washington DC.

Shove, E. (2003) Converging conventions of comfort, cleanliness and convenience. Journal of Consumer Policy 26:395-418.

Smith, A., Stirling, A. and Berkhout, F. (2005). The governance of socio-technical transitions. Research Policy, 34, 1491-150.

Smith, A. and A. Stirling (2007) Moving outside or inside? Objectification and reflexivity in the governance of socio-technical systems Journal of Environmental Policy \& Planning 9, 3-4: 351-373.

Song, J.-W., Kim, J., Yoon, Y.-H., Choi, B.-S., Kim, J.-H. and Han, C.-S. (2008). Inkjet printing of single-walled carbon nanotubes and electrical characterization of the line pattern. Nanotechnology, 19, 095702.

Stirling, A. (2008). Science, Precaution, and the Politics of Technological Risk. Converging Implications in Evolutionary and Social Scientific Perspectives. Annals of the New York Academy of Sciences, 1125:95-110.

Stokes, E. (2009). Regulating nanotechnologies: sizing up the options. Legal Studies, 29(2): 281-304.

UK Government (2009) UK Government response to the Royal Commission on Environmental Pollution (RCEP) Report "Novel materials in the environment: The case of nanotechnology". The Stationary Office, London. Available at http://www.official-documents.gov.uk/document/cm76/7620/7620.pdf . Accessed 11 July 2009. 
Walker, W. (2000) Entrapment in large technological systems: institutional commitment and power relations. Research Policy 29: 833-846.

Williams, R. (2006). Compressed Foresight and Narrative Bias: Pitfalls in Assessing High Technology Futures. Science as Culture, 15(4):327-348.

Wilsdon, J. and Willis, R. (2004). See-through science: why public engagement needs to move upstream. London, Demos.

Wilsdon, J., Wynne, B. and Stilgoe, J. (2005). The Public Value of Science. Or how to ensure that science really matters. London, Demos.

Youtie, J., Iacopetta, M. and Graham, S. (2008) Assessing the nature of nanotechnology: can we uncover an emerging general purpose technology? Journal of Technology Transfer $33: 315-329$ 